\title{
Research on the Policy Optimization Path of Street- Stall Economy Based on Multi-Party Cooperative Game
}

\author{
Xiaoshu Yang* and Haijun Lu \\ School of Economies and Management, Beijing Jiaotong University, China \\ *Xiaoshu Yang. Email: 19120720@bjtu.edu.cn
}

\begin{abstract}
In view of the policy optimization of China's street-stall economy, a three-party dynamic game model of central government, local government and street-stall operators has been established. By solving and analysing the equilibrium solution of the game model, the key factors for the economic optimization of street-stall economy have been discovered, and based on this, a policy optimization path for street-stall economy was constructed. Results showed that how to realize the optimized and standardized management of the street-stall economy is a decision result related to the interest game between the central government, local governments and street-stall operators, and the optimization path can be carried out from three paths: the central government and the local government, the local government and the street-stall operators, and the central government and the street-stall operators.
\end{abstract}

Keywords: Street-stall economy, Multi-party cooperative game, Policy optimization.

\section{INTRODUCTION}

Street-stall economy is an economic form that uses stalls to complete commodity transactions and obtain income [1]. Achieving the standardized operation of street stalls is not only conducive to improving employment and protecting people's livelihood, but also stimulating consumption and promoting the development of real economy. Meanwhile, because street-stall economy will affect the traffic environment, city appearance and living environment to a certain extent, its standardized management also determines whether it can exist for a long time. Effectively stimulating the development of street-stall economy and implementing appropriate and standardized management is related to country's urban governance and social governance. To always promote urban prosperity and ensure the stability of people's livelihoods, the government needs to adjust policies and guide street-stall operators to standardize stalls. However, whether street-stall operators regulate the stall or not is the choice of maximizing his personal interests based on all the external information he knows, which is a kind of interest game behaviour involving multiple subjects.

\section{LITERATURE REVIEW}

Song Tingmin [2] built an evolutionary game model between street-stall operators and urban management based on evolutionary game theory, and analysed the relationship between the interests of the two parties, and believed that the strategic choices of stall vendors and urban management are related to benefits, costs, and penalties. Measures such as improving relevant laws and regulations, reducing the cost of supervision of urban management, and increasing the amounts of fines for merchants' disorderly stalling can well regulate the operation of stalls.

Jia Xiaoyan [3] used a non-cooperative game model with complete information to analyse the probability of vendors' regulated operations under the three conditions of simple fines, issuance of licenses, and assistance to vendors, the probability of urban management inspections, and the expected return value of both parties. Vendors who operate are fined and provide assistance to regulated operators, which can enable vendors to actively choose regulated operations in pursuit of more benefits, and this effect depends on the reputation benefits generated by the government in the process of assistance. 
Xiang Yanren [4] analysed the relationship between urban management and vendors by using pure strategy static game with complete information, and proposed that the interests of all parties should be considered in the process of regulating the operation of the stall.

$\mathrm{Xu}$ Zhaoyong [5] analysed the contradiction between the urban management department and the unlicensed vendors by using the dynamic game under incomplete information, and believed that there is no chance between the two to form a binding agreement game, that is to say, the two parties are pursuing a noncooperative game formed by maximizing self-interest. In order to guide the two to a cooperative game, the government plays a vital role as the interest coordinator of all social strata.

Xin Zhijie [6] used the dynamic game theory to analyse the interest game relationship between local government and stall operators, and found that the effectiveness of local government policies is the key to solving the stall problem, and that standardized management is the main countermeasure to solve the stall problem.

In summary, scholars have conducted lots of research on standardized management of the stall economy, and have obtained rich research results. However, there are still the following shortcomings: First, the standardized management of stalls involves the participation of multiple subjects, while scholars mainly focus on the conflicts between street vendors and urban management, ignoring the role of other participants. Second, it is fundamental to regulate the development of street stalls from a policy perspective, but research on the policy optimization of street-stall economy has not yet formed a system; Third, research based on game theory only involves the players of the two parties, and there is very little research on the game of the three parties. Therefore, this study will use game theory to construct a three-party dynamic game model between the central government, local governments, and street-stall operators, explore the interest game relationship between the three, and further analyse the strategic choices under different conditions, and point out the policy optimization path of the stall economy, and finally provide relevant suggestions.

\section{MODEL CONSTRUCTION}

\subsection{Model Assumptions and Parameter Settings}

Assuming that the participants are the central government (CG), local governments (LG), and streetstall operators (SSO). In the process of street-stall economy optimization, the central government mainly aims to maintain a good image and increase central fiscal revenue via stimulating consumption, the local government mainly aims to improve performance evaluation and promote local economic development via stimulating consumption, while the stall operator is based on the premise of a completely rational economic man, and the maximization of its interests is manifested in an increase in net profit. Moreover, the actions of the three parties have a sequential order, that is, the latter can infer and determine its own actions based on the actions of the former. So, this study constructed a dynamic game model. The parameters and meanings involved are as follows.

\subsubsection{Central Government}

a1: the total revenue the central government receives due to street-stall operators actively participate in the stall operation, when the central government optimizes the street-stall policy.

a2: the total revenue the central government receives due to street-stall operators actively participate in the stall operation, when the central government does not optimize the street-stall policy.

b1: the total revenue the central government receives due to street-stall operators passively participate in the stall operation, when the central government optimizes the street-stall policy.

b2: the total revenue the central government receives due to street-stall operators passively participate in the stall operation, when the central government does not optimize the street-stall policy.

c: the financial subsidies the central government provides to encourage local governments to implement optimized and standardized management policies for street-stall operators.

Besides, a1 $>$ a 2, b1 $=\mathrm{b} 2=\mathrm{b}$.

\subsubsection{Local Government}

d1: the total revenue the local government receives due to street-stall operators actively participate in the stall operation, when the central government optimizes the street-stall policy.

$\mathrm{d} 2$ : the total revenue the local government receives due to street-stall operators actively participate in the stall operation, when the central government does not optimize the street-stall policy.

e1: the total revenue the local government receives due to street-stall operators passively participate in the stall operation, when the central government optimizes the street-stall policy.

e2: the total revenue the local government receives due to street-stall operators passively participate in the stall operation, when the central government does not optimize the street-stall policy. 
f: the financial subsidies local government provides to encourage street-stall operators to regulate stalls.

Besides, $\mathrm{d} 1>\mathrm{d} 2, \mathrm{e} 1=\mathrm{e} 2=\mathrm{e}$.

\subsubsection{Street-Stall Operators}

$\mathrm{g}$ : the net profit in the current state.

$\mathrm{h}$ : the reduced income due to actively participating in the regulation of the stall operation.

i: the added cost due to actively participating in the regulation of the stall operation, including sanitation and cleaning, product quality assurance, equipment improvement, safety and hygiene knowledge learning.

$\mathrm{j}$ : the opportunity cost caused by improper operation, such as, forced prohibition by the government, fines imposed by urban management, and elimination by the market.

Besides, $\mathrm{h}+\mathrm{i}<\mathrm{j}$.

\subsection{Model Assumptions and Parameter Settings}

Central government has two strategies for local governments: one strategy to optimize stall policy to increase the employment rate and to ensure the stability of the people's livelihood, the probability is $\mathrm{x}$; another strategy to not optimize stall policy to increase the employment rate and to ensure the stability of the people's livelihood, the probability is 1-x.

Local governments also have two strategies for street-stall operators by interpreting the policies of the central government and combining local economic development. One strategy is to optimize stall policy to increase employment and promote local economic development, the probability is y; another strategy is not to optimize stall policy increase employment and promote local economic development, the probability is $1-\mathrm{y}$.

Stall operator, according to local government policies, also has two strategies: one strategy to actively operation, the probability is $\mathrm{z}$; another strategy to passively operation, the probability is 1-z. Actively operation means that street-stall operators' operating behaviour complies with the city's management regulations, and passively one means that operating behaviours violate the city's management regulations.

Each game player has two strategy choices, forming eight strategy combinations. The game tree is shown in Figure 1.

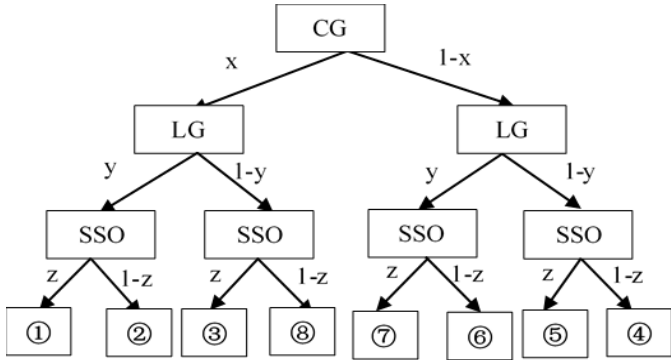

Figure 1 Three-party dynamic game tree

According to the model assumptions and parameter settings, the game matrix is obtained, as shown in Table 1 .

Table 1. Three-party payment matrix

\begin{tabular}{cccc} 
& $c G$ & $1 \mathrm{c}$ & sso \\
\hline (1) & $\Delta_{11}=b+a_{1}-c$ & $\Delta_{12}=e+d_{1}+c-f$ & $\Delta_{13}=g-h+f-i$ \\
(2) & $\Delta_{21}=b-c$ & $\Delta_{22}=e+c$ & $\Delta_{23}=g-j$ \\
(3) & $\Delta_{31}=b+a_{1}$ & $\Delta_{32}=e+d_{2}$ & $\Delta_{33}=g-h-i$ \\
(4) & $\Delta_{41}=b$ & $\Delta_{42}=e$ & $\Delta_{43}=g-j$ \\
(5) & $\Delta_{51}=b+a_{2}$ & $\Delta_{52}=w+d_{1}-f$ & $\Delta_{53}=g-h+f-i$ \\
(6) & $\Delta_{81}=b$ & $\Delta_{62}=e$ & $\Delta_{63}=g-j$ \\
(7) & $\Delta_{71}=b+a_{2}$ & $\Delta_{72}=e+d_{2}$ & $\Delta_{73}=g-h-i$ \\
(8) & $\Delta_{81}=b$ & $\wedge_{82}=e$ & $\wedge_{83}=g-j$ \\
\hline & & &
\end{tabular}

\section{MODEL ANALYSIS}

\subsection{Income Function and Equilibrium Solution}

Backwards induction was adopted in this study Starting from the last stage of the dynamic game, that is, the stall operator, the analysis begins to determine the maximum expected return of the stall operator, and then successively determine the maximum expected return of the local government and the central government to obtain the equilibrium solution of the three game parties.

The total expected revenue of the central government:

$\sum_{C G}=x y z \square_{11}+x y(1-z) \square_{21}+x(1-y) z \square_{31}+$
$x(1-y)(1-z) \square_{41}+(1-x) y z \square_{51}+(1-x) y(1-z) \square_{61}$
$+(1-x)(1-y) z \square_{71}+(1-x)(1-y)(1-z) \square_{81}$

The total expected revenue of the local government:

$\sum_{L G}=x y z \square_{12}+x y(1-z) \square_{22}+x(1-y) z \square_{32}+$

$x(1-y)(1-z) \square_{42}+(1-x) y z \square_{52}+(1-x) y(1-z) \square_{62}$

$+(1-x)(1-y) z \square_{72}+(1-x)(1-y)(1-z) \square_{82}$

The total expected revenue of the stall operator: 


$$
\begin{aligned}
& \sum_{s S O}=x y z \bigsqcup_{13}+x y(1-z) \bigsqcup_{23}+x(1-y) z \bigsqcup_{33}+ \\
& x(1-y)(1-z) \square_{43}+(1-x) y z \square_{53}+(1-x) y(1-z) \square_{63} \\
& +(1-x)(1-y) z \square_{73}+(1-x)(1-y)(1-z) \square_{83}
\end{aligned}
$$

Using the idea of derivation, find the equilibrium solution of the expected income of the stall operator, that is $\frac{\partial \sum_{s s o}}{\partial z}=0, \sum_{s s o}$ achieves the maximum value. At this time:

$y=\frac{h-j+i}{f}$

In the same way, find the equilibrium solution of the expected income of local government and local government, as shown in equations (2) and (3):

$x=\frac{\left(f-d_{1}+d_{2}\right) z}{c}$

$z=\frac{c y}{a_{1}-a_{2}}$

After calculation, the equilibrium solution of the central government, local government and street-stall operators in the game model is obtained as:

$\left(x^{*}, y^{*}, z^{*}\right)=\left\{\frac{\left(f-d_{1}+d_{2}\right)(h-j+i)}{\left(a_{1}-a_{2}\right) f}, \frac{h-j+i}{f}, \frac{c(h-j+i)}{\left(a_{1}-a_{2}\right) f}\right\}$

\subsection{Analysis of Game Equilibrium Solution}

\subsubsection{Analysis of Equilibrium Solution of Stall Operator}

$\mathrm{z}$ and $\mathrm{c}$ are proportional. When local governments are entrusted by the central government to implement stall optimization policies, the more incentive policies and financial subsidies they receive from the central government, the more they can actively respond to the call of the central government, and the more they can actively optimize and standardize stall policies and encourage local stall operators to actively conduct standardized operations.

If $\mathrm{z}>0$, then there is $h+i>j$. So, the government must increase the financial subsidy given to street-stall operators, and the subsidy amount must be able to make up for the difference between $\mathrm{h}+\mathrm{i}$ and $\mathrm{j}$, otherwise street-stall operators will choose to passively participate in standardized stalls with the goal of maximizing their own interests.

\subsubsection{Analysis of Equilibrium Solution of Local Government}

If $\mathrm{y}>0$, then there is $h+i>j$. Same as the above conclusion. If $\mathrm{y}<1$, then there is $h-j+i<f$, and $\mathrm{y}$ and $\mathrm{f}$ is inversely proportional. That means, when the supportive financial subsidy granted by the local government to street-stall operators is too high, it will negatively affect their performance appraisal, which will reduce the probability that they will choose to optimize the stall policies.

Besides, $\mathrm{y}$ is proportional to $\mathrm{h}$ and $\mathrm{i}$, and inversely proportional to $\mathrm{j}$. That means, the more the profit that the street-stall operators reduce by actively operation, and the greater the cost for sanitation, product quality assurance, and equipment improvement, the higher the possibility that the local government will optimize stall policy. The greater the opportunity loss for stall operators who do not conduct standardized operations, such as forced ban by the government, fines from urban management investigations, and market elimination, the greater their self-consciousness in conducting standardized stall operations. At this time, the local government will decrease the probability to make optimization stall policy.

\subsubsection{Analysis of Equilibrium Solution of Central Government}

$$
\frac{\partial x}{\partial f}=\frac{(h-j+i)\left(d_{1}-d_{2}\right)}{\left(a_{1}-a_{2}\right) f^{2}}, h+i>j \text {, that is } \frac{\partial x}{\partial f}>0, \mathrm{x} \text { and }
$$

$f$ are proportional, which indicates that the optimization stall policy of the local government requires strong financial support from the relevant policies of the central government.

Besides, $\mathrm{x}$ is proportional to $\mathrm{h}$ and $\mathrm{i}$, and inversely proportional to $\mathrm{j}$. That means, the more the profit that street-stall operators reduce by actively operation, and the greater the cost for sanitation, product quality assurance, and equipment improvement, the higher the possibility that the central government will optimize stall policy to improve the employment status and ensure the stability of the people's livelihood. The greater the opportunity loss for street-stall operators who do not conduct standardized operations, such as forced ban by the government, fines from urban management investigations, and market elimination, the greater their self-consciousness in conducting standardized stall operations. At this time, the central government will decrease the probability to make optimization stall policy.

$\mathrm{x}>0,{ }^{h-j}+i>0$, then is $f>d_{1}-d_{2}$. That means, the local government's supportive financial subsidies to the street-stall operators must be greater than the difference between $\mathrm{d} 1$ and $\mathrm{d} 2$, otherwise the local government will choose not to optimize the stall policy and not give the street-stall operators the corresponding supportive financial subsidies because the loss of their own interests exceeds the profit. 


\section{OPTIMIZATION PATH ANALYSIS AND POLICY RECOMMENDATIONS}

\subsection{Optimization Path Analysis}

From the above analysis, we can see that the central government, local governments, and street-stall operators play an important role in the policy optimization of street-stall economy. As shown in Figure 2, on path a, the inclination of the central government's policies and the strong financial support play an important role in guiding local governments to optimize street-stall economy; on path $b$, the local government interprets and implements the central government's policies as an agent, which plays a pivotal role in realizing the standardized management of streetstall economy. How to attract more street-stall operators to actively participate in standardized stalls and legally balance the interest relationship with other subjects is a key issue for local governments; on path c, the central government makes full use of its own economic functions to formulate a series of macro-control policies to improve and protect the basic legitimate rights and interests of street-stall operators.

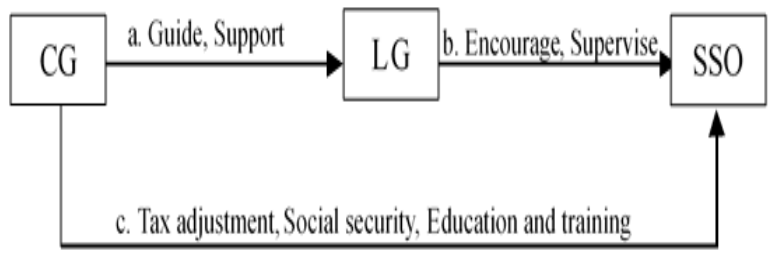

Figure 2 Policy optimization path of street-stall economy

\subsection{Related Policy Recommendations}

\subsubsection{Establish and Improve Relevant Laws and Regulations}

For path a, given that the development of our country's stall economy is still in its infancy and a more systematic legal system has not yet been formed, governments can learn from the advanced experience of South Korea, Japan and other foreign countries, and formulate and improve laws based on country's actual conditions. At the same time, the assessment content of local governments should be appropriately added, and street-stall economy can be included in the scope of the assessment to guide local governments to make a difference in the development of local stalls.

\subsubsection{Increase Support}

For path a, central governments should increase support for local governments and street-stall operators. Standardize operations often means reduced profits due to shortened stalls, reduced stall options, and increased environmental protection equipment costs, which makes street-stall operators' willingness to actively participate is generally low. In order to maintain the stall economy order, local governments will increase supervision costs or increase financial support expenditures, which requires central government to give as much resource support and policy favours as possible.

\subsubsection{Encourage Other Social Organizations to Participate}

For path $b$, local governments can formulate relevant incentive policies to encourage other social organizations to actively participate in the standardized operation of street stalls. For example, appropriately introduce social entrepreneurs, providing employment guidance, legal consultation, skills training and other related material support; encourage the participation of community people, realizing public supervision of the operation of stalls; encourage internet celebrities to conduct live webcasts of model stall areas, which can try to develop into local tourist attractions.

\subsubsection{Improve the Market Supervision System}

For path $b$, the local government should improve the market supervision system and realize the social cogovernance of the stall economy. It is necessary to pay attention to the interaction between government and non-government entities, and establish and improve a feedback mechanism for stall management including urban managers, community residents, street-stall operators and other diverse entities to ensure that relevant policies can be truly implemented. Additionally, the local government must take into account the support policy of "teaching people to fish", and increase training on hygiene and safety awareness and vocational education awareness of street vendors.

\subsubsection{Implement Control Policies}

For path c, the central government must implement a series of macro-control policies. Use fiscal policy tools, such as reducing tax reductions and exemptions to increase the income level of street-stall operators; and build a multi-level social security system to protect the basic legal rights of street-stall operators (especially low-income groups); improve the legal identity of street-stall operator in the form of laws and regulations. At the same time, education and vocational training should be launched for young and middle-aged stall operators to expand their livelihood and job search channels. At the same time, the government should also strengthen the publicity and education of street-stall operators, so that more people understand the importance of regulating operations, and increase their awareness of maintaining urban environmental order and market economic order. 


\section{CONCLUSION}

The stall economy market is still immature. The standardized management of the stall economy is also the result of a decision made by a game of interests involving multiple subjects. The optimization of the stall economy requires the coordination and cooperation of the central government, local governments and stall operators, and cannot be carried out in isolation of any one subject. In order to promote the standardized management of the stall economy in my country, it can be achieved through the following optimization paths: establish and improve relevant laws and regulations, improve the legal identity of stall operations; increase support; encourage other social organizations to participate, and seek a balance of interests between local governments and stall operators; improve the market supervision system and realize the social co-governance of the stall economy; implement a series of control policies to protect the basic legitimate rights and interests of stall operators.

\section{REFERENCES}

[1] Gong Yezhu. Research on the economic development status and management countermeasures of Qingdao stalls [D]. Ocean University of China, 2011:11-13.
[2] Song Tingmin. Analysis of urban management problems based on evolutionary game theory $[\mathrm{J}]$. Journal of Chongqing Technology and Business University (Natural Science Edition), 2019, 36(02): 61-66.

[3] Jia Xiaoyan, Shou Zhimin. Analysis of the contradiction between urban management and merchants based on game theory $[\mathrm{J}]$. Financial Economy, 2012(20): 12-15.

[4] Xiang Yanren, $\mathrm{Fu}$ Xinhong. Analysis of the relationship between urban management and small vendors from the perspective of game theory [J]. Modern Business, 2011(03): 170-171.

[5] Xu Zhaoyong, Dai Yun. Research on Cooperative Game in Urban Management-Conflict Resolution between Urban Management Department and Unlicensed Vendors [J]. Urban Development Research, 2010, 17(09): 4-6.

[6] Xin Zhijie. Game Theory Thinking on "Road Economy" [J]. Journal of Hunan Radio and Television University, 2010(04):67-70. 